\title{
Alkylation of Ethyl Pyruvate via Reductive Coupling of Alkenes and Ethyl 2-(Benzenesulfonylamino)acrylate
}

\author{
Vincent Darmency§ and Philippe Renaud* \\ §SCS Poster Prize Winner
}

\begin{abstract}
Radical coupling of B-alkylcatecholboranes, in situ generated from the corresponding alkenes, with ethyl 2-(benzenesulfonylamino)acrylate is reported. This reaction represents an extension of the radical allylation of Balkylcatecholboranes by allylsulfones. This unique process allows the preparation of various $\alpha$-ketoesters (alkylated pyruvates) in a straightforward manner. It also demonstrates the generality of the radical mediated $\mathrm{C}-\mathrm{C}$ bond formation starting from organoboranes and allylic benzenesulfonyl derivatives.
\end{abstract}

Keywords: Alkylation · Enamides · Hydroboration · Organoboranes · Radical reactions · Sulfonamides

The development of methods for tin-free radical mediated $\mathrm{C}-\mathrm{C}$ bond formation is currently an area of great interest. B-Alkylcatecholboranes are particularly promising reagents for the generation of alkyl radicals [1][2]. They have been employed as radical precursors for conjugate addition to enones/ enals [3] and unsaturated esters [4] as well as for intramolecular cyclization processes [5]. Recently, we reported an efficient procedure for the allylation of organoboranes (Scheme 1) based on the use of allylsulfones [6]. This chain reaction takes advantage of the rapid $\beta$-fragmentation of 2-benzenesulfonylalk-1-yl radicals and of the efficient reaction of benzenesulfonyl radicals with B-alkylcatecholboranes.

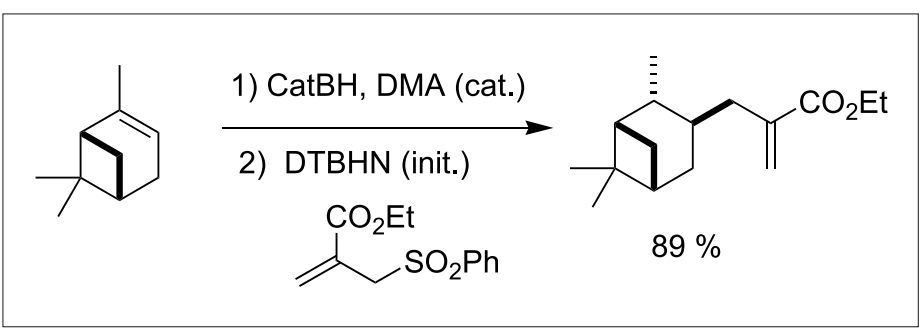

Scheme 1

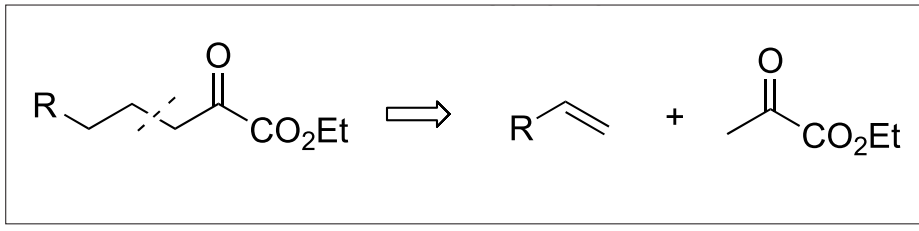

Scheme 2.

Zard and coworkers reported that the radical reaction of $\alpha$-xanthylketones and ethyl 2-(ethanesulfonylamino)acrylate affords an intermediate $\gamma$-ketimine which spontaneously ring-closes to form pyrroles derivatives [7]. This reaction involves the radical $\beta$-fragmentation of an ethanesulfonyl radical from a sulfonamide. The final step of the chain process involves a xanthate transfer from the radical precursor to the ethyl radical generated from the ethanesulfonyl radical by loss of $\mathrm{SO}_{2}$. Here, we report a related process involving the coupling of B-alkylcatecholboranes with ethyl 2-(benzenesulfonylamino)acrylate. This reaction represents a novel method for the alkylation of ethyl pyruvate with alkenes (Scheme 2).

B-Alkylcatecholboranes are easily prepared by hydroboration of alkenes with catecholborane according to the efficient and cost-effective conditions developed by Garett and Fu [8]. Ethyl 2-(benzenesulfony lamino)acrylate was treated with different in situ generated B-alkylcatecholboranes (2 equiv.) in dichloroethane using di-tertbutylhyponitrite or air as initiator [9]. The transient ketimine was never observed and is presumably hydrolyzed during the chromatography purification and the corre- 


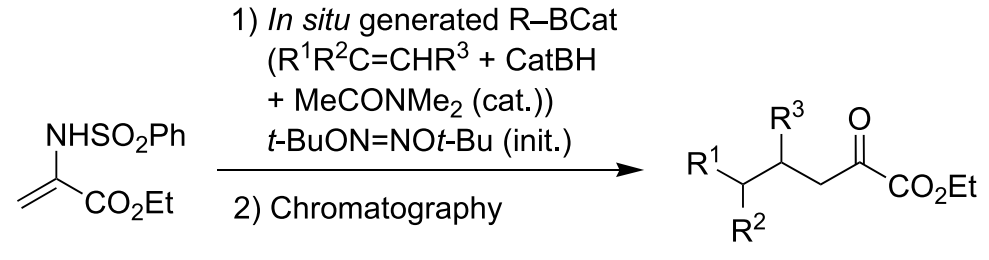

Scheme 3.

Table. Reductive coupling of alkenes and ethyl 2-(benzenesulfonamino)acrylate under radical conditions according to Scheme $3^{\text {a }}$

Entry $\mathrm{R}^{1} \mathrm{R}^{2} \mathrm{C}=\mathrm{CHR}^{3}$

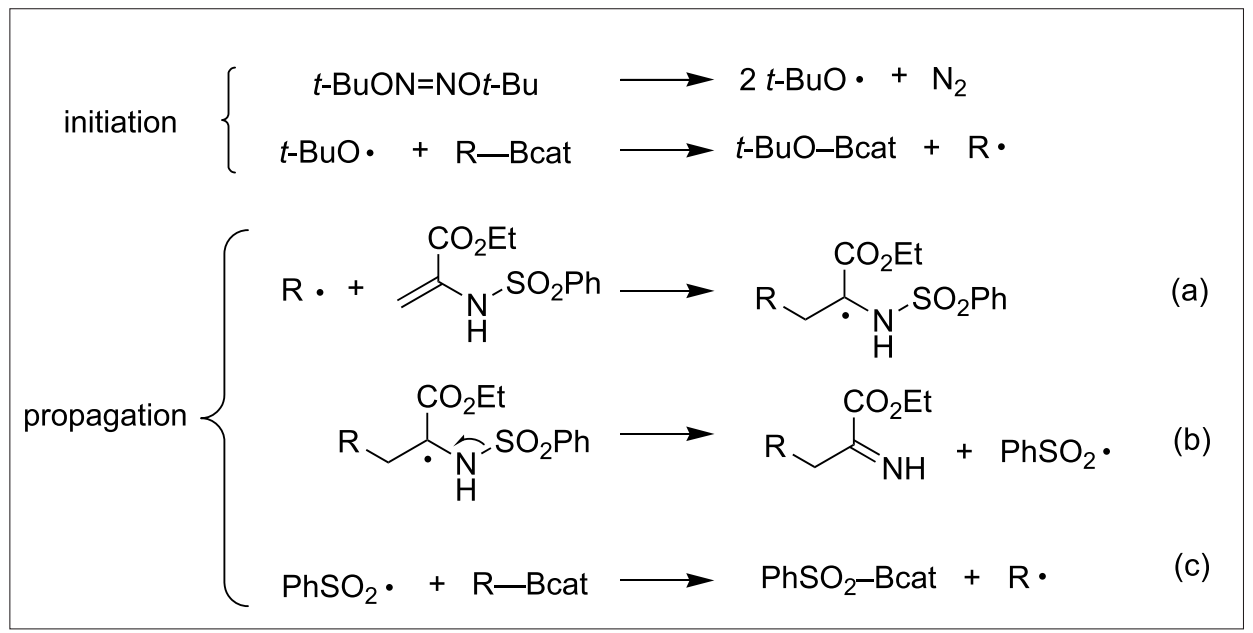

Scheme 4

sponding $\alpha$-ketoester are isolated (Scheme 3 , Table). The best results are obtained in dichloroethane using di-tert-butylhyponitrite as initiator, however, the yield does not exceed $32 \%$ for $(+)-\alpha$-pinene (Table, entry 3 ).

The mechanism of this transformation is depicted in Scheme 4. Decomposition of the di-tert-butylhyponitrite affords the tertbutoxyl radical that reacts with the B-alkylcatecholborane to produce the desired alkyl radical. This radical enters then the propagation steps (a)-(c) according to Scheme 4.
A possible side reaction involving the addition of the sulfonyl radical to ethyl 2-(benz enesulfonylamino)acrylate may explain the moderate yield of the process [10]. However, no side product resulting from this reaction has been identified.

In conclusion, we have shown that coupling of organoboranes with sulfonylenamides is possible and may be used for the preparation of alkylated pyruvates. This unique transformation is so far giving only modest yields but represents an attractive alternative to classical alkylation proce- dures. This demonstrates further the generality of the sulfonyl radical mediated reaction of organoboranes. The extension of this fragmentation chemistry to other classes of $\mathrm{C}-\mathrm{C}$ bond formation such as vinylation, acylation, cyanation and alkynylation of Balkylcatecholboranes will be reported soon.

\section{Acknowledgments}

This work was supported by the Swiss National Science Foundation. We thank BASF Corporation for the generous gift of catecholborane.

Received: January 25, 2005

[1] A.-P. Schaffner, P. Renaud, Eur. J. Org. Chem. 2004, 2291.

[2] A.-P. Schaffner, B. Becattini, C. Ollivier, V. Weber, P. Renaud, Synthesis 2003 , 2740.

[3] C. Ollivier, P. Renaud, Chem. Eur. J. 1999, 5, 1468.

[4] C. Ollivier, P. Renaud, Angew. Chem. Int. Ed. 2000, 39, 925.

[5] B. Becattini, C. Ollivier, P. Renaud, Synlett 2003, 1485.

[6] A.-P. Schaffner, P. Renaud, Angew. Chem. Int. Ed. 2003, 42, 2658.

[7] B. Quiclet-Sire, F. Wendeborn, S.Z. Zard, Chem. Commun. 2002, 2214.

[8] C.E. Garett, G.C. Fu, J. Org. Chem. 1996 61, 3224

[9] Typical experimental procedure: Catecholborane $(533 \mu \mathrm{l}, 5.0 \mathrm{mmol})$ was added dropwise at $0{ }^{\circ} \mathrm{C}$ to a solution of (+)- $\alpha$-pinene $(317 \mu \mathrm{l}, 2.0 \mathrm{mmol})$ and $\mathrm{N}, \mathrm{N}$-dimethylacetamide $(18 \mu \mathrm{l}, 0.2 \mathrm{mmol})$ in dry 1,2-dichloroethane $(2 \mathrm{ml})$ under stirring and inert atmosphere. The resulting colorless solution was heated under reflux for $5 \mathrm{~h}$. The reaction mixture was carefully quenched at $0{ }^{\circ} \mathrm{C}$ with dry methanol $(200$ ul) and stirred $15 \mathrm{~min}$ at room temperature. Ethyl 2-(benzenesulfonamino)acrylate (255 mg, $1.0 \mathrm{mmol}$ ) was added followed by di-tert-butylhyponitrite $(9 \mathrm{mg})$. The resulting yellow mixture was stirred under reflux for $4 \mathrm{~h}$ until a black coloration appeared. Every $1 \mathrm{~h}$, a portion of di-tert-butylhyponitrite $(9 \mathrm{mg}$ ) was added. The alkylated pyruvate $(80 \mathrm{mg}, 32 \%)$ was obtained after purification by flash chromatography (hexane/ethyl acetate 95:5).

[10] W.R. Hertler, J. Org. Chem. 1974, 39, 3219 . 